\title{
Article
}

\section{Athletic Performance and Recovery- Stress Factors in Cycling: An Ever Changing Balance}

Edson, Filho, Selenia, Di Fronso, Fabio, Forzini, Mauro, Murgia, Tiziano, Agostini, Laura, Bortoli, Claudio, Robazza and Maurizio, Bertollo

Available at http://clok.uclan.ac.uk/11978/

Edson, Filho ORCID: 0000-0002-8548-4651, Selenia, Di Fronso, Fabio, Forzini, Mauro, Murgia, Tiziano, Agostini, Laura, Bortoli, Claudio, Robazza and Maurizio, Bertollo (2015) Athletic Performance and Recovery-Stress Factors in Cycling: An Ever Changing Balance. European Journal of Sport Science, 15 (8). pp. 671-680. ISSN 1746-1391

It is advisable to refer to the publisher's version if you intend to cite from the work. http://dx.doi.org/10.1080/17461391.2015.1048746

For more information about UCLan's research in this area go to

http://www.uclan.ac.uk/researchgroups/ and search for <name of research Group>.

For information about Research generally at UCLan please go to http://www.uclan.ac.uk/research/

All outputs in CLoK are protected by Intellectual Property Rights law, including Copyright law. Copyright, IPR and Moral Rights for the works on this site are retained by the individual authors and/or other copyright owners. Terms and conditions for use of this material are defined in the policies page. 
We sought to examine whether the relationship between recovery-stress factors and performance would differ at the beginning (Stage 1) and the end (Final Stage) of a multi-stage cycling competition. Sixty-seven cyclists with a mean age of 21.90 years $(S D=1.60)$ and extensive international experience participated in the study. The cyclists responded to the Recovery-Stress Questionnaire for Athletes (RESTQ-Sport) and rated their performance $(1=$ extremely poor to $10=$ excellent) in respect to the first and last stage. Two step-down multiple regression models were used to estimate the relationship among recovery (nine factors; e.g., Physical Recovery, Sleep Quality) and stress factors (10 factors; e.g., Lack of Energy, Physical Complaints), as assessed by the RESTQ and in relation to performance. Model-1 pertained to Stage 1, whereas Model-2 used data from the Final Stage. The final Model-1 revealed that Physical Recovery $(\beta=.46, p=.01)$, Injury $(\beta=-.31, p=.01)$ and General Well-being $(\beta=-.26$, $p=.04)$ predicted performance in Stage $1\left(R^{2}=.21\right)$. The final Model-2 revealed a different of time, and dynamically influences performance in multi-stage competitions. 


\section{Athletic Performance and Recovery-Stress Factors in Cycling:}

\section{An Ever Changing Balance}

The ability to balance recovery demands and stress stimuli is essential for the development and maintenance of skilled performance in sports (Kellmann, 2010; Meeusen et al., 2013). Chronic underrecovery may lead to non-functional overreaching and, ultimately, to overtraining and burnout (Meeusen et al., 2013). Accordingly, monitoring recovery-stress balance is crucial to sport scientists and professionals (Di Fronso, Nakamura, Bortoli, Robazza, \& Bertollo, 2013; Kellmann, 2002). Previous studies on recovery-stress balance have been based primarily on pre-post mean comparison designs, thus capturing changes in recovery and stress but failing to assess the relationship among various recovery (e.g., sleep quality, social relaxation) and stress factors (e.g., emotional, social). However, the relationship among biopsycho-social variables and performance outcomes should not be drawn on a one-to-one basis (Cacioppo, Tassinary, \& Berntson, 2007), but rather on a one-to-many basis, in the sense that performance is usually influenced by multiple bio-psycho-social factors (Edmonds \& Tenenbaum, 2012).

Within the sport and exercise psychology domain, the importance of concurrently assessing various recovery and stress factors is presented in Kellmann’s (2002) Model of the Interrelation between Stress States and Recovery Demands. In theory, Kellmann posits that the interrelation among recovery demands and stress states should be balanced if athletes aim to perform optimally during competitions. In practice, it means that upon an increase in stressors throughout the season (e.g., social stress such as pressure from coaches and media), athletes should counterbalance by engaging in various forms of passive (e.g., sleeping in), active (e.g., stretching) and pro-active (e.g., travelling to visit family and friends) recovery activities. When 
unable to balance recovery demands and stress states (i.e., high stress/low recovery; low stress/high recovery), athletes are more likely to perform poorly.

Kellmann's Model of the Interrelation between Stress States and Recovery Demands has been psychometrically operationalized through the Recovery-Stress Questionnaire for Athletes (RESTQ-Sport; for a review Kellmann \& Kallus, 2001). This questionnaire is composed of general stress (e.g., Physical Complaints) and recovery scales (e.g., Physical Recovery), as well as sport specific stress (e.g., Injury) and recovery (e.g., Self-Efficacy) scales. The RESTQ-Sport was designed to target athletes', rather than coaches', subjective perception of recovery factors and stress states. This is particularly important because athletes' and coaches' assessment of training load tends to differ (Ardua \& Márquez, 2007). Furthermore, the RESTQ-Sport has been used by sport scientists and practitioners, as it allows for the establishment of a multilayered recovery-stress profile (Davis, Orzeck, \& Keelan, 2007; Di Fronso et al., 2013; Lombardi et al., 2013).

Previous research on recovery-stress balance in sports has focused on comparing recovery-stress scores (pre-post designs) across different training periods (e.g., pre-season, inseason, post-season). Overall, results suggest that recovery and stress scores fluctuate greatly throughout the competitive season (Brink, Visscher, Coutts, \& Lemmink, 2012; Di Fronso et al., 2013; Kellmann, Altenburg, Lormes, \& Steinacker, 2001). In regards to elite cyclists, underrecovery has been found to be negatively related to performance and perception of effort (Halson et al., 2002). Furthermore, recovery-stress unbalance has been found to have a strong negative effect on Olympic cyclists’ performance (Gould \& Dieffenbach, 2002). Maintaining a healthy recovery-stress balance is paramount in multi-stage competitions, when athletes are exposed to high-stress demands over extensive periods of time (Filho et al., 
2013; Lombardi et al., 2013). In particular, cyclists’ performance and perceived bio-psychosocial states have been found to vary greatly over multi-stage competitions (Filho et al., 2013).

Moreover, the different environmental characteristics proper to each competition stage have been shown to influence athletes’ overall performance capability (Lombardi et al., 2013). In this context, we aimed to explore the relationship between cyclists’ bio-psycho-social states and performance in a multi-stage cycling competition. Specifically, we aimed at addressing the question: "Does the relationship among several perceived recovery-stress states and performance outcomes change in a multi-stage cycling competition?” More specifically, we sought to examine whether the relationship among recovery-stress factors and performance would differ at the beginning (i.e., stage 1) and end (i.e., final stage) of the Girobio, an international multi-stage cycling competition. Given the exploratory nature of our study, we refrained from proposing specific hypotheses. We expected that the final regression models for the first and last stages would differ akin to the overarching theoretical notion that recovery-stress factors are dynamic and tend to change greatly over time (Kellmann, 2010).

\section{Methods}

\section{Participants}

Institutional ethical approval was obtained prior to the commencement of the study, and in agreement with the Helsinki Declaration. All athletes participating in the Girobio-2012 were briefed on the purposes of the study during the technical meeting preceding the start of the race. Cyclists interested in the study received further information about its objectives and procedures, and signed an informed consent sheet. Of the 170 cyclists who entered the Girobio-2012, 78 finished the race and agreed to complete the two administrations of the RESTQ-Sport. On average, the cyclists had 11.23 years of cycling experience $(S D=5.90)$ and were approximately 22 years of age $(M=21.90, S D=1.60)$. The cyclists were from four different countries (i.e., 
93 Italy, Netherlands, Switzerland, and United States) and represented 25 different racing teams.

94 The majority of the cyclists who participated in the study were puncheurs $(n=38,48.7 \%)$,

followed by all-rounders $(n=13,16.7 \%)$, climbers $(n=12,15.4 \%)$ and sprinters $(n=3,3.8 \%)$.

96 Twelve cyclists (15.4\%) did not report their riding specialty.

\section{Measures} team affiliation was collected. Athletes were also asked to indicate what type of cyclists (all-

100

101

102

103

104

105

106

107

108

109

110

111

112

113

114 rounder, climber, puncheur, or sprinter) they considered themselves to be.

RESTQ-Sport (Kellmann \& Kallus, 2001). The RESTQ-Sport was designed to measure

the frequency that athletes experience stress states as well as recovery-related activities and contains 77 items pertaining to 19 scales. Specifically, the RESTQ-Sport consists of (a) seven general stress scales (i.e., General Stress, Emotional Stress, Social Stress, Conflicts/Pressure, Fatigue, Lack of Energy, Physical Complaints), (b) five general recovery scales (i.e., Success, Social Recovery, Physical Recovery, General Well-being, Sleep-Quality), (c) three stress sportspecific scales (i.e., Disturbed Breaks, Emotional Exhaustion, Injury), and (d) four sport-specific recovery scales (i.e., Being in Shape, Personal Accomplishment, Self-Efficacy, Self-Regulation). Each scale contains four items, measured using a Likert-type scale with anchors 0 (never) and 6 (always). All items were preceded by the stem "in the past 3 days/nights...”, and worded in simple language aimed at facilitating grammatical understanding. Sample items include: “I was angry with someone” (Social Stress), and "I had a good time with my friends” (Social Recovery). Previous psychometric assessments have supported the factorial structure (i.e., recovery and stress), internal consistency, and test-retest reliability of the RESTQ-Sport (Davis et al., 2007; 
115 116 127 individuals' role within a team.

\section{Procedures}

Kellmann \& Kallus, 2001). Moreover, the questionnaire has high face and predictive validity in regards to underrecovery and overtraining states in sports (Kellmann \& Kallus, 2001).

Performance. Subjective performance represented the dependent variable in the stepdown regression analysis adopted in this study. After the completion of the first and final stage, the athletes were asked to report their perceived performance on a Likert scale ranging from 1 (extremely poor) to 10 (excellent). It is important to note that subjective reports may better represent athletes' performance experiences in some sports (Chelladurai, 2007). Purely objective scores do not account for myriad situational factors, such as outstanding performance from peers and opponents, bad weather, and stage conditions (e.g., flat, low-mountain, and high-mountain). In the present study, final ranking was negatively correlated with subjective performance for both Stage 1 (Spearman's $r=-.33$ ) and Stage 2 (Spearman's $r=-.39$ ), corroborating the notion that objective and subjective performance are not positively related constructs, and dependent on

Data were collected during the Girobio-2012. The race included nine stages of various lengths and diverse topographies, and covered approximately 1,300 kilometers (for a review see Lombardi et al., 2013). The stages varied in length and involved flat (Stages 1, 2 and 7), lowmountain (Stages 3, 4, 5 and 6), and high-mountain (Stages 8 and 9) terrains. Specifically, the stages ranged from $75.6 \mathrm{~km}$ to $193.3 \mathrm{~km}$ in length $(M=148.82, S D=33.67)$, and from $642 \mathrm{~m}$ to $5190 \mathrm{~m}$ in elevation $(M=2617.78, S D=1576.93)$. The first assessment of the athletes' RESTQSport (Stage 1), as well as the administration of the demographic survey, occurred one day prior to the first stage of the race. The second assessment (Final Stage) occurred one day prior to the last stage. Whereas RESTQ-Sport data was collected prior to the race, performance data was 
138 collected immediately following the first and last stage in congruence with the notion that

139 athletes' subjective reports tend to be more reliable when reported closely after performance

140 (Tenenbaum, Lloyd, Pretty, \& Hanin, 2002). During all data collections the cyclists were

141 instructed to be serious and truthful in their responses. Two trained scholars administered the

142 questionnaires in a quiet environment. Coaches and journalists were not allowed in the room

143 during the data collection to ensure the comfort and privacy of the participants. The interval

144 between stages was 10 days. This time frame was deemed appropriate as the RESTQ-Sport is a

145 state-oriented measure aimed at capturing recovery and stress states over a period of

146 approximately three days or nights (see Kellmann \& Kallus, 2001).

147

148

149

150

151

152

153

154

155

156

157

158

159

160

\section{Results}

\section{Descriptive and Correlational Analyses}

Means, standard deviations, and correlation coefficients for all recovery and stress factors are given in Table 2 (Stage 1) and Table 3 (Final Stage). Overall, correlation coefficients among stress related factors (general and sport specific) were higher than coefficients among stress and

recovery factors. Similarly, coefficients among recovery factors (general and sport specific) were higher among themselves, than in comparison to scores among recovery and stress related factors. Specifically, significant correlations among general stress scales ranged from .31 (Social Stress and Fatigue) to .70 (General Stress and Social Stress) for Stage 1, and from .28 (Social Stress and Fatigue) to .69 (Emotional Stress and Lack of Energy) for the Final Stage. Correlation coefficients for sport-specific stress scales were between .39 (Emotional Exhaustion and Injury) and .47 (Disturbed Breaks and Emotional Exhaustion) for Stage 1, and between .45 (Disturbed Breaks and Injury) to .60 (Emotional Exhaustion and Injury) for the Final Stage. Correlation coefficients among general recovery scales ranged from .33 (Social Recovery and Physical 
Recovery) to .58 (Physical Recovery and General Well-being) for Stage 1, and from .39 (Success and Social Recovery) to .68 (Social Recovery and General Well-being) for the Final Stage. Lastly, correlation coefficients for sport-specific stress scales were between .65 (Being in Shape and Self-Efficacy) and .71 (Being in Shape and Self-Regulation) for Stage 1, and .58 (Being in Shape and Personal Accomplishment) to .75 (Being in Shape and Self-Regulation) for the Final Stage. Altogether, these findings indicate that the relationship among recovery and stress factors is subject to change over time. To examine how such a relationship could have a varying degree of influence on performance from Stage 1 to the Final Stage, we performed a series of step-down multiple regression analyses.

\section{Regression Analyses}

We adopted a step-down regression analysis, which is considered a robust procedure as it combines theory and data driven approaches (Cohen, Cohen, West, \& Aiken, 2002). Foremost, this analytical approach is consistent with the importance of exploring the dynamic balance involving recovery and stress factors, in respect to performance in sports (Filho et al., 2013; Kellmann, 2010; Meeusen et al., 2013; Shrier \& Hallé, 2011).

All assumptions were checked prior to running the regression analysis. Residuals were randomly dispersed around the independent variables. The outcome variables were relatively normally distributed with skewness and kurtosis values of -.29 and -.47 for Stage 1, and .64 and .33 for the Final Stage. As presented in Tables 2 and 3, correlation among variables was below the cutoff point of .80 ( $r=-.69$ to .46$)$, suggesting that multicollinearity was not a major concern. Estimates of internal consistency were also computed for each scale in regards to Stage 1 and the Final Stage. Scales with poor internal consistency (i.e., $\alpha \leq .60$ ) were not entered in the regression models to prevent biases due to large measurement error (Cohen et al., 2002). 
184 185

Specifically, the scales Success, Physical Complaints and Personal Accomplishment were not included in the analysis for Stage 1, whereas Physical Complaints and Sleep Quality were not considered in the analysis for the Final Stage.

For both stages, demographic variables were entered in the first exploratory model (Model 1) to control for and assess the influence of age and type of cyclist. Whereas age is a continuous variable, type of cyclists was sub-divided and dummy coded for all-rounders $(0=$ no, $1=$ yes $)$, climbers $(0=$ no, $1=$ yes $)$, puncheurs $(0=$ no, $1=$ yes $)$, and sprinters $(0=$ no, $1=$ yes $)$. Any variable that reached marginal significance was retained in the exploratory Model 2, which also included all recovery and stress related factors. Subsequently, all significant predictors of performance, as well as variables with marginal significance, $.05 \leq p \geq .15$, were further tested in Model 3 akin to previous research in the sport literature (Umbach, Palmer, Kuh, \& Hannah, 2006). Congruent with guidelines on parsimonious statistical modeling (Cohen et al., 2002), Final Model 4 contained only significant predictors contributing to explained variance and overall model fit.

Stage 1. Model 1 included demographic variables only, precisely age and type of cyclists. Model 1 did not reach statistical significance, $F(5,69)=1.93, p=.10$. However, the dummy variable sprinter ( $\beta=-.23, p=.07$ ) approached significance and was retained and included in Model 2 along with all recovery and stress factors. Although Model 2 reached statistical significance, $F(17,60)=1.79, p=.05$, the variable sprinter and the majority of the recovery and stress factors were not statistically related to performance (see Table 4). In adopting a conservative approach, we kept all predictors with $p \leq .15$ in Model 3, due to the fact that the partial correlation among predictors may change as variables are eliminated from the regression model (Cohen et al., 2002). Although Model 3 was statistically significant, $F(5,72)=4.66, p=$ 
.01 , Conflicts/Pressure, and Fatigue were still not found to predict performance for $p \leq .05$.

Accordingly, we retained only significant predictors in Model 4, F $(3,74)=6.43, p=.01$.

Specifically, Physical Recovery ( $\beta=.44, p=.01)$, Injury $(\beta=-.31, p=.01)$, and General Wellbeing ( $\beta=-.26, p=.04$ ), were found to significantly predict $21 \%$ of the variance in subjective performance for Stage 1 (see Table 4). Tolerance and variance inflation values were below 1.0 and 2.0, respectively, further suggesting that multicollinearity was not an issue.

Final Stage. We adopted the same rationale for regressing demographic variables and recovery-stress factors onto performance scores. Although Model 1 reached statistical significance, $F(5,69)=2.43, p=.04$, only the dummy variable climber was statistically related to performance. Accordingly, in Model 2 we retained climber while adding all recovery and stress factors to the regression equation. Model 2 did not converge to a reliable solution, $F$ (18, $59)=1.48, p=.13$. In Model 3 we maintained all predictors that had approached significance (i.e., $p \leq .15$ ) in Model 2. Specifically, Model 3 included climber, Conflicts/Pressure, Lack of Energy and Self-Efficacy. Although Model 3 was statistically significant, $F(4,73)=4.63, p=$ .01, Self-Efficacy failed to reach significant results and was excluded from the Final Model 4, F $(3,74)=5.87, p=.01$. Only climber $(\beta=.28, p=.01)$, Conflicts $/$ Pressure $(\beta=.33, p=.01)$, and Lack of Energy ( $\beta=-.37, p=.01$ ) were found to predict performance for the Final Stage. The total explained variance was 19\% (see Table 4). Tolerance and variance inflation values were .64 and 1.57, respectively, and thus multicollinearity was not an issue.

\section{Discussion}

We examined whether the relationship between recovery-stress factors and performance would differ at the beginning and end of a multi-stage cycling competition. Initial correlational analyses suggested that the relationship among recovery and stress factors changed over time. Overall, the correlation pattern across recovery and stress factors was unique for Stage 1 and the 
231 Final Stage. However, the association between Being in Shape and Self-Regulation was of strong 232 magnitude $(r \leq .70)$ for both Stage 1 and the Final Stage. In fact, the ability to self-regulate is 233 essential to enable individuals to stay physically and mentally fit (Filho et al., 2013; Robazza, 234 Pellizzari, \& Hanin, 2004). Therefore, future studies should further examine the direction of this 235 relationship to determine whether self-regulation enables Being in Shape or vice-versa. Step236 down multiple regression models further indicated that the relationship among recovery and 237 stress factors changed greatly from the first to the last stage of the race.

\section{$238 \quad$ Stage 1}

For Stage 1 , Physical Recovery $(\beta=.44)$ was the most important predictor of performance, followed by Injury $(\beta=-.31)$ and General Well-being $(\beta=-.26)$. To this extent, it

241 is well-established that athletes should be (and feel) physically recovered in the competitive

242 phase of the periodization cycle; this being the reason why tapering occurs prior to major

243 competitions (Di Fronso et al., 2013; Gould \& Dieffenbach, 2002; Kellmann, 2010). It has also

244 been empirically established that athletes without injuries usually outperform their opponents

245 (Meeusen et al., 2013; Shrier \& Hallé, 2011).

The negative relationship between General Well-being and performance, a seemly

247 counterintuitive relationship, may be a result of the four items of this scale ("I was in good

248 spirits”; “I was in a good mood”; “I felt happy”; and "I felt content”) measuring affective states

249 rather than general bio-psycho-social health status. In this regard, extant research on the

250 Individual Zones of Optimal Functioning framework suggests that athletes are able to perform

251 optimally even under unpleasant affective states (Hanin, 2007). From an applied standpoint, this

252 finding reinforces the notion that sport practitioners should help athletes to identify their

253 idiosyncratic affective profile, as pleasant emotions are not always linked to optimal 
254 performance. In fact, recent research in sport psychology suggests that athletes should have

255 multi-action plans in order to cope with unpleasant states while sustaining exertion in endurance

256 cycling (Comani et al., 2014).

257 Final Stage

For the Final Stage, climber was found to be positively related to performance. It is

259 understandable that climbers perceived performance differently than other types of riders, given

260 that the final stage was a high-mountain stage, where climbers would likely perform well.

261 Overall, it is noteworthy that different types of cyclists may perceive performance differently and 262 that these differences are likely related to contextual factors (i.e., type of stage, such as flat, low263 mountain, and high-mountain). In fact, there is empirical evidence across sports that one’s role 264 within a team influences subjective performance ratings (Carron, Eys, \& Burke, 2007; Filho, 265 Gershgoren, Basevitch, \& Tenenbaum, 2014). Accordingly, both researchers and practitioners 266 should consider self-perceived subjective ratings in designing research and operationalizing 267 periodization cycles in sports.

For the Final Stage, Lack of Energy and Conflicts/Pressure were found to be negatively 269 and positively related to performance, respectively. Thus, the ability to mobilize all available 270 mental and physical energy resources is crucial for optimal performance at the end of the race.

271 Mental skills regimens, in particular relaxation routines and attention control training (see Orlick, 272 2008), may help athletes replenish energy prior to the final stage, and save energy during the race 273 by focusing on certain cues. The positive relationship between Conflicts/Pressure and 274 performance has ample support in both classic and contemporary sport psychology literature 275 (Eklund \& Tenenbaum, 2013; Jones, Swain, \& Hardy, 1993). Sport psychologists have long 276 argued that pressure to perform ("fight or flight”) may be facilitative rather than debilitative to 
277 athletic performance, particularly among elite athletes participating in high-stakes competition

278 (Fletcher \& Hanton, 2001; Swain \& Jones, 1996). Cyclists that made it to the last stage may have

279 adopted a positive frame of mind, choosing to embrace the pressure and stay committed to the 280 race (mindfulness-acceptance approach; see Gardner \& Moore, 2004), rather than abandoning 281 the stage.

Generally, findings from this study suggest that the linkage between recovery-stress 283 factors and performance is dynamic in nature, an ever-changing balance. These findings 284 corroborate the notion that athletes’ performance in multi-stage competitions are partially 285 dependent on their self-perceived bio-psycho-social states (Di Fronso et al., 2013; Filho et al., 286 2013). During multi-stage competitions athletes are exposed to different challenges (e.g., 287 different terrains and temperatures) that influence their ability to consistently obtain peak 288 performance while maintaining a healthy recovery-stress balance. Thus, coaches and sport 289 practitioners should closely monitor how changes in athletes’ bio-psycho-social profile influence 290 performance in multi-stage competitions. Athletes with little competitive experience and 291 minimal coping skills may benefit greatly from receiving specific feedback about how to balance 292 recovery and stress during extensive multi-stage competitions.

\section{Limitations, Implications and Future Directions}

This study is not without limitations. First, we were unable to collect additional 295 psychological and physiological data, as time with the athletes was limited. Second, the 296 relatively small sample size might have interfered with the reliability of a few RESTQ-Sport 297 scales, as previously detailed. We adopted a convenience sample strategy by collecting data in 298 situ. Ideally, future studies should be based on larger sample sizes defined through a priori power 299 analysis. Notwithstanding, the complexity of a field study with elite cyclists during an extended, 
multi-stage competition made it difficult to collect data for a larger number of athletes while including multiple methodological controls.

Despite these limitations, our study advanced research in sport and exercise psychology by looking at the relationship of recovery-stress factors rather than focusing primarily on mean comparison. From a theoretical standpoint, our findings reinforce the notion that performance is influenced by myriad recovery-stress factors that are not stable, but rather change dynamically over relatively short periods of time (Kellmann, 2002, 2010; Kellmann \& Kallus, 2001). It is particularly noteworthy that general recovery factors explained most of the variance of performance in the First Stage, whereas general stress factors were more relevant in the Final Stage. From an applied standpoint, these findings highlight the importance of considering the interaction of recovery-stress factors when developing periodization programs in sports. It is important to ensure that athletes are fully recovered prior to competition in agreement with the overarching notion of training periodization. Moreover, coping skills might be particularly important in multi-day competitions, especially during the final stages.

In addition to targeting larger samples and implementing multiple psycho-physiological controls, future studies should consider mid-race assessments that can be statistically integrated with pre- and post-assessments through longitudinal growth models. Researchers should also compare top to bottom cyclists' objective performance markers (i.e., time, final rank) in order to advance the knowledge of recovery and stress factors as predictors of expert performance in cycling. Moreover, additional studies comparing the bio-psycho-social profile of the different types of cyclists may advance specific performance psychology guidelines applied to allrounders, climbers, puncheurs, and sprinters. Specifically, scholars could examine whether different types of cyclists favor different recovery strategies (i.e., active, passive, pro-active). 
323 The inclusion of other psychological measures, such as rating of perceived exertion, and

324 physiological assessments may help to form a more complete understanding of recovery-stress

325 balance in endurance sports. Finally, investigating the relationship of recovery-stress factors with

326 group-related constructs (e.g., cohesion in cycling teams) and objective performance may

327 advance our knowledge on the profile of high-performing teams in endurance sports. 


\section{References}

330

Ardua, C., \& Márquez, S. (2007). Relation between coaches leadership style and performance in synchronous swimming. Fitness \& Performance Journal (Online Edition), 6, 394-397. doi:10.3900/fpj.6.6.394.e

Brink, M. S., Visscher, C., Coutts, A. J., \& Lemmink, K. A. (2012). Changes in perceived stress and recovery in overreached young elite soccer players. Scandinavian Journal of Medicine \& Science in Sports, 22, 285-292. doi:10.1111/j.1600-0838.2010.01237.x

Cacioppo, J. T., Tassinary, L. G., \& Berntson, G. G. (2007). Psychophysiological science: Interdisciplinary approaches to classic questions about the mind. In J. T. Cacioppo, L. G. Tassinary, \& G. Berntson (Eds.), Handbook of psychophysiology (3rd ed., pp. 1-24). New York, NY: Cambridge University Press.

Carron, A. V., Eys, M. A., \& Burke, S. M. (2007). Team cohesion: Nature, correlates, and development. In S. Jowette \& D. Lavallee (Eds.), Social psychology in sport (pp. 91102). Champaign, IL: Human Kinetics.

Chelladurai, P. (2007). Leadership in sports. In G. Tenenbaum \& R. C. Eklund (Eds.), Handbook of sport psychology (3rd ed., pp. 113-135). Hoboken, NJ: John Wiley \& Sons.

Cohen, J., Cohen, P., West, S. G., \& Aiken, L. S. (2002). Applied multiple regression/correlation analysis for the behavioral sciences (3rd ed.). London, UK: Routledge.

Comani, S., Di Fronso, S., Filho, E., Castronovo, A. M., Schmid, M., Bortoli, L., ...Bertollo, M. (2014). Attentional focus and functional connectivity in cycling: An EEG case study. International Federation for Medical and Biological Engineering, 41, 131-144. 
Davis IV, H., Orzeck, T., \& Keelan, P. (2007). Psychometric item evaluations of the recoverystress questionnaire for athletes. Psychology of Sport and Exercise, 8, 917-938. doi:10.1016/j.psychsport.2006.10.003

Di Fronso, S., Nakamura, F. Y., Bortoli, L., Robazza, C., \& Bertollo, M. (2013). Stress and recovery balance in amateur basketball players: Differences by gender and preparation phase. International Journal of Sports Physiology \& Performance, 8, 618-622.

Edmonds, W. A., \& Tenenbaum, G. (Eds.). (2012). Case studies in applied psychophysiology: Neurofeedback and biofeedback treatments for advances in human performance. Hoboken, NJ: Wiley-Blackwell.

Eklund R., \& Tenenbaum, G. (Eds.). (2013). Encyclopedia of sport and exercise psychology. Thousand Oaks, CA: Sage Publications.

Filho, E., Di Fronso, S., Forzini, F., Agostini, T., Bortoli, L., Robazza, C., \& Bertollo, M. (2013). Stress/recovery balance during the Girobio: Profile of highly trained road cyclists. Sport Sciences for Health, 9, 107-112. doi:10.1007/s11332-013-0153-x

Filho, E., Gershgoren, L., Basevitch, I., \& Tenenbaum, G. (2014). Profile of high-performing college soccer teams: An exploratory multi-level analysis. Psychology of Sport and Exercise, 15, 559-568. doi:10.1016/j.psychsport.2014.05.008 1469-0292

Fletcher, D., \& Hanton, S. (2001). The relationship between psychological skills usage and competitive anxiety responses. Psychology of Sport and Exercise, 2, 89-101. doi: 10.1016/S1469-0292(00)00014-5

Gardner, F. L, \& Moore, Z. E. (2004). A Mindfulness-Acceptance-Commitment-based approach to athletic performance enhancement: Theoretical considerations. Behavior Therapy, 35, 707-723. doi:10.1016/S0005-7894(04)80016-9 
373 Gould, D., \& Dieffenbach, K. (2002). Overtraining, under recovery, and burnout in sport. In M. Kellmann (Ed.), Enhancing recovery: Preventing underperformance in athletes (pp. 2535). Champaign, IL: Human Kinetics.

Halson, S. L., Bridge, M. W., Meeusen, R., Busschaert, B., Gleeson, M., Jones, D. A., \& Jeukendrup, A. E. (2002). Time course of performance changes and fatigue markers during intensified training in trained cyclists. Journal of Applied Physiology, 93, 947956.

Hanin, Y. L. (2007). Emotions in sport: Current issues and perspectives. In G. Tenenbaum, \& R. C. Eklund (Eds.), Handbook of sport psychology (3rd ed., pp. 31-58). Hoboken, NJ: Wiley \& Sons.

Jones, G., Swain, A., \& Hardy, L. (1993). Intensity and direction dimensions of competitive state anxiety and relationships with performance. Journal of Sports Sciences, 11, 525-532.

Kellmann, M. (2010). Preventing overtraining in athletes in high-intensity sports and stress/recovery monitoring. Scandinavian Journal of Medicine \& Science in Sports, 20, 95-102. doi:10.1111/j.1600-0838.2010.01192.x

Kellmann, M. (2002). Underrecovery and overtraining: Different concepts - similar impact? In M. Kellmann (Ed.), Enhancing recovery: Preventing underperformance in athletes (pp. 3-24). Champaign, IL: Human Kinetics.

Kellmann, M., Altenburg, D., Lormes, W., \& Steinacker, J. M. (2001). Assessing stress and recovery during preparation for the world championships in rowing. The Sport Psychologist, 15, 151-167.

Kellmann, M., \& Kallus K. W. (2001). Recovery-stress questionnaire for athletes. Champaign, IL: Human Kinetics. 
Lombardi, G., Lanteri, P., Fiorella, P., Simonetto, L., Impellizzeri, F. Bonifazi, M.,... Locatelli, M. (2013). Comparison of the hematological profile of elite road cyclists during the 2010 and 2012 GiroBio ten-day stage races and relationships with final ranking. Plos One (4), e63092.

Meeusen, R., Duclos, M., Foster, C., Fry, A., Gleeson, M., Nieman, D., ... Urhausen, A. (2013). Prevention, diagnosis and treatment of the overtraining syndrome: Joint consensus statement of the European College of Sport Science (ECSS) and the American College of Sports Medicine (ACSM). European Journal of Sport Science, 13, 1-24. doi:10.1080/17461391.2012.730061

Orlick, T. (2008). In pursuit of excellence (4th ed.). Champaign, IL: Human Kinetics.

Robazza, C., Pellizzari, M., \& Hanin, Y. (2004). Emotion self-regulation and athletic performance: An application of the IZOF model. Psychology of Sport and Exercise, 5, 379-404. doi:10.1016/S1469-0292(03)00034-7

Shrier, I., \& Hallé, M. (2011). Psychological predictors of injuries in circus artists: An exploratory study. British Journal of Sports Medicine, 45, 433-436. doi:10.1136/bjsm.2009.067751

Swain, A., \& Jones, G. (1996). Explaining performance variance: The relative contribution of intensity and direction dimensions of competitive state anxiety. Anxiety, Stress \& Coping: An International Journal, 9, 1-18.

Tenenbaum, G., Lloyd, M., Pretty, G., \& Hanin, Y. L. (2002). Congruence of actual and retrospective reports of precompetition emotions in equestrians. Journal of Sport \& Exercise Psychology, 24, 271-288. 
418 Umbach, P. D., Palmer, M. M., Kuh, G. D., \& Hannah, S. J. (2006). Intercollegiate athletes and 419 effective educational practices: Winning combination or losing effort? Research in Higher Education, 47, 709-733. doi:10.1007/s11162-006-9012-9

421 
1 Table 1

2 Descriptive and Correlational Matrix of Stress and Recovery Factors, Girobio Stage 1

\begin{tabular}{|c|c|c|c|c|c|c|c|c|c|c|c|c|c|c|c|c|c|c|c|c|c|c|}
\hline Stress / Recovery & M & SD & 1 & 2 & 3 & 4 & 5 & 6 & $7^{\dagger}$ & 8 & 9 & 10 & $11^{\dagger}$ & 12 & 13 & 14 & 15 & 16 & $17^{\dagger}$ & 18 & 19 & 20 \\
\hline \multicolumn{23}{|l|}{ General Stress } \\
\hline 1. General Stress & 0.89 & 0.92 & 1 & $.60^{*}$ & $.62^{*}$ & $.55^{*}$ & $.49^{*}$ & $.57^{*}$ & & $.45^{*}$ & $.69^{*}$ & .21 & & -.22 & $-.28^{*}$ & $-.42^{*}$ & $-.26^{*}$ & $-.23^{*}$ & & -.14 & -.17 & -.11 \\
\hline 2. Emotional Stress & 1.17 & 0.94 & & 1 & $.70^{*}$ & $.40^{*}$ & $.41^{*}$ & $.62^{*}$ & & $.32^{*}$ & $.54^{*}$ & $.29^{*}$ & & $-.24^{*}$ & -.17 & $-.45^{*}$ & $-.39^{*}$ & -.10 & & -.08 & -0.2 & .02 \\
\hline 3. Social Stress & 1.10 & 1.10 & & & 1 & $.34^{*}$ & $.31^{*}$ & $.63^{*}$ & & $.36^{*}$ & $.58^{*}$ & .13 & & -.09 & -.16 & $-.35^{*}$ & $-.28^{*}$ & -.13 & & .07 & -.09 & -.02 \\
\hline 4. Conflicts/Pressure & 2.07 & 1.11 & & & & 1 & $.41^{*}$ & $.42^{*}$ & & $.42^{*}$ & $.30^{*}$ & $.24^{*}$ & & -.06 & -.01 & -.17 & $-.25^{*}$ & .06 & & -.06 & .04 & -.14 \\
\hline 5. Fatigue & 1.44 & 0.96 & & & & & 1 & $.36^{*}$ & & $.44^{*}$ & $.57^{*}$ & $.50^{*}$ & & -.04 & $-.25^{*}$ & -.20 & $-.43^{*}$ & -.12 & & -.09 & .03 & -.12 \\
\hline $\begin{array}{l}\text { 6. Lack of Energy } \\
\text { 7. Physical Complaints }\end{array}$ & 1.09 & 0.80 & & & & & & 1 & & $.37^{*}$ & $.55^{*}$ & $.36^{*}$ & & -.11 & -19 &.$-36^{*}$ & $-.26^{*}$ & -.12 & & -.05 & -.10 & -.08 \\
\hline \multicolumn{23}{|l|}{ Sport Specific Stress } \\
\hline $\begin{array}{l}\text { 8. Disturbed Breaks } \\
\text { 9. Emotional }\end{array}$ & 1.27 & 0.92 & & & & & & & & 1 & $.47^{*}$ & $.40^{*}$ & & -.02 & -.09 & $-.24^{*}$ & $-.28^{*}$ & -.19 & & -.08 & -.16 & $-.23^{*}$ \\
\hline Exhaustion & 1.22 & 0.97 & & & & & & & & & 1 & $.39^{*}$ & & -.09 & $-.24^{*}$ & $-.25^{*}$ & $-.31^{*}$ & -.13 & & -.03 & -.03 & $-.22^{*}$ \\
\hline 10. Injury & 1.84 & 0.78 & & & & & & & & & & 1 & & .15 & .01 & .01 & -.19 & .19 & & .15 & $.25 *$ & $-.28^{*}$ \\
\hline \multicolumn{23}{|l|}{ General Recovery } \\
\hline 12. Social Recovery & 3.55 & 1.26 & & & & & & & & & & & & 1 & $.33^{*}$ & $.49^{*}$ & .11 & $.28^{*}$ & & .10 & $.32^{*}$ & -.03 \\
\hline 13. Physical Recovery & 3.03 & 0.93 & & & & & & & & & & & & & 1 & $.58^{*}$ & $.46^{*}$ & $.68^{*}$ & & $.61^{*}$ & $.64^{*}$ & $.27^{*}$ \\
\hline 14. General Well-being & 3.54 & 1.12 & & & & & & & & & & & & & & 1 & $.44^{*}$ & $.68^{*}$ & & $.61^{*}$ & $.64^{*}$ & -.01 \\
\hline 15. Sleep Quality & 3.94 & 0.89 & & & & & & & & & & & & & & & 1 & $.39^{*}$ & & $.35^{*}$ & $.24^{*}$ & .17 \\
\hline Sport Specific Recovery & & & & & & & & & & & & & & & & & & & & & & \\
\hline $\begin{array}{l}\text { 16. Being in Shape } \\
\text { 17. Personal } \\
\text { Accomplishment }^{\dagger}\end{array}$ & 3.22 & 1.14 & & & & & & & & & & & & & & & & 1 & & $.65^{*}$ & $.79^{*}$ & .17 \\
\hline 18. Self-Efficacy & 2.86 & 1.07 & & & & & & & & & & & & & & & & & & 1 & $.73^{*}$ & .18 \\
\hline 19. Self-Regulation & 3.10 & 1.12 & & & & & & & & & & & & & & & & & & & 1 & .16 \\
\hline 20. Performance & 5.82 & 2.27 & & & & & & & & & & & & & & & & & & & & 1 \\
\hline
\end{tabular}

3 *p<.05;**p<.01

4 Note. ${ }^{\dagger}$ These scales were not considered in the analysis of Stage 1 due to low internal consistency (i.e., $\alpha \leq .60$ ).

5 
1 Table 2

2 Descriptive and Correlational Matrix of Stress and Recovery Factors, Final Stage

3

\begin{tabular}{|c|c|c|c|c|c|c|c|c|c|c|c|c|c|c|c|c|c|c|c|c|c|c|}
\hline Stress / Recovery & $\mathrm{M}$ & SD & 1 & 2 & 3 & 4 & 5 & 6 & $7^{\dagger}$ & 8 & 9 & 10 & 11 & 12 & 13 & 14 & $15^{\dagger}$ & 16 & 17 & 18 & 19 & 20 \\
\hline \multicolumn{23}{|l|}{ General Stress } \\
\hline 1. General Stress & 1.82 & 1.29 & 1 & $.63^{*}$ & $.45^{*}$ & $.56^{*}$ & $.49^{*}$ & $.60^{*}$ & & $.47^{*}$ & $.68^{*}$ & $.47 *$ & .12 & -.17 & -.18 & $-.41^{*}$ & & -.15 & .06 & .00 & -.07 & -06 \\
\hline 2. Emotional Stress & 1.76 & 1.19 & & 1 & $.65^{*}$ & $.60^{*}$ & $.38^{*}$ & $.69^{*}$ & & $.42^{*}$ & $.53^{*}$ & $.34^{*}$ & $.24^{*}$ & -.12 & -.06 & $-.34^{*}$ & & -.02 & .12 & .09 & .04 & -.06 \\
\hline 3. Social Stress & 1.88 & 1.47 & & & 1 & $.42^{*}$ & $.28^{*}$ & $.67^{*}$ & & .22 & $.44^{*}$ & $.24^{*}$ & $.23^{*}$ & .01 & .01 & -.11 & & .06 & .07 & .11 & .04 & -.14 \\
\hline 4. Conflicts/Pressure & 2.12 & 1.09 & & & & 1 & $.41^{*}$ & $.60^{*}$ & & $.37^{*}$ & $.49^{*}$ & $.34^{*}$ & $.48^{*}$ & $.25^{*}$ & .11 & -.07 & & .19 & $.27^{*}$ & $.25^{*}$ & $.26^{*}$ & .14 \\
\hline 5. Fatigue & 2.90 & 1.46 & & & & & 1 & $.30^{*}$ & & $.61^{*}$ & $.55^{*}$ & $.64^{*}$ & $.28^{*}$ & .13 & -.08 & -.02 & & .02 & $.31^{*}$ & $.28^{*}$ & .21 & -.08 \\
\hline $\begin{array}{l}\text { 6. Lack of Energy } \\
\text { 7. Physical Complaints }\end{array}$ & 1.48 & 0.95 & & & & & & 1 & & $.37^{*}$ & $.50^{*}$ & $.28^{*}$ & $.35^{*}$ & -.05 & -.04 & -16 & & .07 & .08 & .14 & .03 & -.17 \\
\hline \multicolumn{23}{|l|}{ Sport Specific Stress } \\
\hline 8. Disturbed Breaks & 2.41 & 1.40 & & & & & & & & 1 & $.46^{*}$ & $.45^{*}$ & .20 & .12 & -.04 & -.11 & & .04 & $.28^{*}$ & $.28^{*}$ & .20 & -.11 \\
\hline 9. Emotional Exhaustion & 1.98 & 1.18 & & & & & & & & & 1 & $.60^{*}$ & .11 & -.07 & -.20 & -.22 & & .01 & .01 & .05 & -.07 & -.14 \\
\hline 10. Injury & 2.64 & 1.23 & & & & & & & & & & 1 & .16 & .20 & -.07 & .06 & & -.05 & .22 & .19 & .11 & -.17 \\
\hline \multicolumn{23}{|l|}{ General Recovery } \\
\hline 11. Success & 2.17 & 1.13 & & & & & & & & & & & 1 & $.39^{*}$ & $.54^{*}$ & $.43^{*}$ & & $.59^{*}$ & $.56^{*}$ & $.67^{*}$ & $.62^{*}$ & .10 \\
\hline 12. Social Recovery & 3.18 & 1.35 & & & & & & & & & & & & 1 & $.48^{*}$ & $.68^{*}$ & & $.53^{*}$ & $.62^{*}$ & $.49^{*}$ & $.56^{*}$ & .15 \\
\hline 13. Physical Recovery & 2.42 & 0.93 & & & & & & & & & & & & & 1 & $.58^{*}$ & & $.66^{*}$ & $.44^{*}$ & $.56^{*}$ & $.61^{*}$ & .09 \\
\hline $\begin{array}{l}\text { 14. General Well-being } \\
\text { 15. Sleep Quality }\end{array}$ & 2.91 & 1.20 & & & & & & & & & & & & & & 1 & & $.59^{*}$ & $.43^{*}$ & $.41^{*}$ & $.52^{*}$ & .15 \\
\hline Sport Specific Recovery & & & & & & & & & & & & & & & & & & & & & & \\
\hline $\begin{array}{l}\text { 16. Being in Shape } \\
\text { 17. Personal }\end{array}$ & 2.57 & 1.18 & & & & & & & & & & & & & & & & 1 & $.58^{*}$ & $.73^{*}$ & $.75^{*}$ & .11 \\
\hline Accomplishment & 2.46 & 1.16 & & & & & & & & & & & & & & & & & 1 & $.64^{*}$ & $.71^{*}$ & .15 \\
\hline 18. Self-Efficacy & 2.52 & 1.14 & & & & & & & & & & & & & & & & & & 1 & $.74^{*}$ & -.09 \\
\hline 19. Self-Regulation & 2.70 & 1.20 & & & & & & & & & & & & & & & & & & & 1 & .14 \\
\hline 20. Performance & 6.42 & 1.60 & & & & & & & & & & & & & & & & & & & & 1 \\
\hline
\end{tabular}

$4 \quad{ }^{*} p<.05 ; * * p<.01$

5 Note. ${ }^{\dagger}$ These scales were not considered in the analysis of the Final Stage due to low internal consistency (i.e., $\alpha \leq .60$ ). 
$1 \quad$ Table 3

2 Regression Analysis of Stress and Recovery Factors on Cycling Performance, Stage 1

\begin{tabular}{|c|c|c|c|c|c|c|c|c|c|c|c|c|}
\hline \multirow{2}{*}{ Variables } & \multicolumn{3}{|c|}{ Model 1} & \multicolumn{3}{|c|}{ Model 2} & \multicolumn{3}{|c|}{ Model 3} & \multicolumn{3}{|c|}{ Model 4 (Final) } \\
\hline & $\mathrm{B}$ & $\beta$ & $p$ & $\mathrm{~B}$ & $\mathrm{~B}$ & $p$ & $\mathrm{~B}$ & $\beta$ & $p$ & $\mathrm{~B}$ & $\beta$ & $p$ \\
\hline \multicolumn{13}{|c|}{ Demographics } \\
\hline Age & .13 & .10 & .43 & & & & & & & & & \\
\hline All-rounder & -1.19 & -.19 & .19 & & & & & & & & & \\
\hline Climber & 1.03 & .17 & .26 & & & & & & & & & \\
\hline Puncheur & -.18 & -.04 & .82 & & & & & & & & & \\
\hline Sprinter & -3.21 & -.23 & .07 & .22 & .02 & .88 & & & & & & \\
\hline
\end{tabular}

General Stress

General Stress

Emotional Stress

Social Stress

Conflicts/Pressure

Fatigue

Lack of Energy

$\begin{array}{lll}.14 & .06 \quad .77\end{array}$

$\begin{array}{lll}.29 & .12 & .52\end{array}$

$\begin{array}{lll}-.05 & -.02 & .89\end{array}$

$\begin{array}{lll}-.53 & -.26 & .10\end{array}$

$\begin{array}{lll}-.36 & -.18 & .12\end{array}$

$\begin{array}{lll}.70 & .30 & .06\end{array}$

$\begin{array}{lll}.49 & .21 & .12\end{array}$

Phys. Complaints ${ }^{\dagger}$

$\begin{array}{lll}.30 & .10 \quad .52\end{array}$

Sport-Specific

Stress

Disturbed Breaks

Emot. Exhaustion

$\begin{array}{lll}-.11 & -.04 & .76\end{array}$

Injury

$\begin{array}{lll}-.58 & -.25 & .18\end{array}$

$\begin{array}{lll}-1.23 & -.42 & .01\end{array}$

$\begin{array}{lllll}-1.10 & -.37 & .01 & -.89 & -.31\end{array}$

.01

General Recovery

Success $^{\dagger}$

Social Recovery

Phys. Recovery

Gen. Well-being

Sleep Quality

$\begin{array}{rrrrrrrrr}.06 & .04 & .79 & & & & & & \\ .82 & .33 & .06 & 1.24 & .51 & .01 & 1.07 & .44 & .01 \\ -.89 & -.44 & .03 & -.58 & -.29 & .03 & -.52 & -.26 & .04 \\ .20 & .08 & .58 & & & & & & \end{array}$

Sport-Specific

Recovery

Being in Shape

Person. Accomp. ${ }^{\dagger}$

Self-Efficacy

$\begin{array}{lll}.54 & .27 \quad .22\end{array}$

Self-Regulation

$\begin{array}{lll}-.17 & -.08 \quad .66\end{array}$

$.30 \quad .15 \quad .52$

\begin{tabular}{lllll}
$R^{2}$ & .12 & $.34^{*}$ & $.24^{* *}$ & $.21^{* *}$ \\
\hline${ }^{*} p<.05 ;{ }^{* *} p<.01$ & & &
\end{tabular}

4 Note. ${ }^{\text {}}$ These scales were not considered in the analysis of Stage 1 due to low internal consistency values. 
$1 \quad$ Table 4

2 Regression Analysis of Recovery and Stress Factors on Cycling Performance, Final Stage

3

\begin{tabular}{|c|c|c|c|c|c|c|c|c|c|c|c|c|}
\hline \multirow{2}{*}{ Variables } & \multicolumn{3}{|c|}{ Model 1} & \multicolumn{3}{|c|}{ Model 2} & \multicolumn{3}{|c|}{ Model 3} & \multicolumn{3}{|c|}{ Model 4 (Final) } \\
\hline & B & $\beta$ & $p$ & B & B & $p$ & B & $\beta$ & $p$ & $\mathrm{~B}$ & $\beta$ & $p$ \\
\hline \multicolumn{13}{|c|}{ Demographics } \\
\hline Age & .03 & .04 & .76 & & & & & & & & & \\
\hline All-rounder & .14 & .03 & .83 & & & & & & & & & \\
\hline Climber & 1.16 & .38 & .01 & 1.0 & .23 & .09 & 1.16 & .26 & .01 & 1.22 & .28 & .01 \\
\hline Puncheur & .37 & .11 & .49 & & & & & & & & & \\
\hline Sprinter & -1.52 & -.15 & .21 & & & & & & & & & \\
\hline
\end{tabular}

General Stress

General Stress

$\begin{array}{lll}.21 & .17 \quad .38\end{array}$

Emotional Stress

$\begin{array}{lll}.02 & .01 & .94\end{array}$

Social Stress

$\begin{array}{lll}-.09 & -.08 & .61\end{array}$

Conflicts/Pressure

$\begin{array}{lll}.48 & .33 & .09\end{array}$

$\begin{array}{rrr}.07 & .06 & .72\end{array}$

Fatigue

$-.50 \quad-.30 \quad .14$

$\begin{array}{llllll}.53 & .36 & .01 & .48 & .33 & .01\end{array}$

Lack of Energy

Phys. Complaints ${ }^{\dagger}$

$\begin{array}{llllll}-.62 & -.37 & .01 & -.62 & -.37 & .01\end{array}$

Sport-Specific

Stress

Disturbed Breaks

$\begin{array}{lll}-.05 & -.05 & .75\end{array}$

Emot. Exhaustion

$\begin{array}{lll}-.11 & -.08 & .66\end{array}$

Injury

$\begin{array}{lll}-.20 & -.15 & .38\end{array}$

General Recovery

Success

$\begin{array}{rrr}.03 & .02 & .91\end{array}$

Social Recovery

$\begin{array}{lll}-.08 & -.07 & .74\end{array}$

Phy. Recovery

$\begin{array}{lll}-.05 & -0.3 & .85\end{array}$

Gen. Well-being

$\begin{array}{lll}.27 & .20 & .36\end{array}$

Sleep Quality ${ }^{\dagger}$

Sport Specific

Recovery

Being in Shape

Person. Accomp.

$\begin{array}{lll}.17 & .12 & .56\end{array}$

$\begin{array}{lll}.33 & .24 & .21\end{array}$

Self-Efficacy

$\begin{array}{lll}-.55 & -.39 & .08\end{array}$

$\begin{array}{lll}-.15 & -.10 & .34\end{array}$

Self-Regulation

$\begin{array}{lll}.05 & .04 & .87\end{array}$

.15

.31

$.20 * *$

$.19^{* *}$

$4 \stackrel{R^{2}}{{ }^{*} p<.05 ;{ }^{* *} p<.01}$

5 Note. ${ }^{\text {T}}$ These scales were not considered in the analysis of the Final-Stage due to low internal consistency values. 